\title{
Screening of extracellular polymeric substance producing bacteria isolated from environmental sources and testing their ability to seal fractures zones of oil reservoir rocks
}

\author{
Asaad Faraj Hamzah ${ }^{1}$, Wijdan Hussein Al-Tamimi ${ }^{2}$ \\ \{asaadfaraj@yahoo.com ${ }^{1}$,wijdanhussien@gmail.com ${ }^{2}$ \} \\ Technical institute of Basrah, Southern Technical University, Basrah, Iraq ${ }^{1}$. \\ Departments of Biology, Science Collage, University of Basrah, Basrah, Iraq ${ }^{2}$.
}

\begin{abstract}
In this study, 21 environmental bacterial isolates isolated from different environmental sources in Basra Governorate identified phenotypically and genetically based on 16 rRNA gene sequence analysis were screened to reveal their ability to produce biopolymer based on the viscosity scale formed in the cultural media and use of Sudan Black stain. Six isolates showed their ability to produce biopolymer, and the two isolates of Bacillus licheniformis strain CC91, Bacillus thuringiensis strain LU3 recorded the best results. The isolate of the Bacillus licheniformis strain CC91 was tested in the process of sealing fractures and openings with high permeability for samples of oil reservoir rocks.
\end{abstract}

Keywords: biopolymer, byproducts, MEOR, petroleum microbiology.

\section{Introduction}

Biopolymers are polymers produced derived from natural renewable resources synthesized by either microorganisms under different environmental conditions or chemically synthesized from a biological material [1][2]. Biopolymers they are composed by monomeric units covalently linked to form larger structures of Biopolymers [3].Often the production of polysaccharides biopolymer by bacteria for the purpose of protecting from desiccation conditions or the risk of predation by other microbes as well as to assist in adhesion to surfaces [4][5]. Ates ,2015 [6] mentioned that in 1861 Pasteur was the first noticed the production of dextran polymer in wine by bacteria, the first person to identify this bacterium Leuconostoc mesenteriodes was Van Tieghem in the year 1878. Bio-polymers have now gained much attention due to their importance in industrial sectors all over the world [7][8]. Many bacteria can produce different types of biopolymers such as Bacillus sp. produce Levan [9], Xanthomonas sp. produce Xanthan gum [10], Sclerotium sp. Produce Scleroglucan ( [11] and many others [4]. The proposed processes of biopolymers in microbial enhanced oil recovery (MEOR) are application in indirectly reducing water mobility towards undesirable zones due to the ability of some microorganism to produce viscous biopolymers (Nwidee et al., 2016 [12] ; Song et al.,2020[13]). Because these zones take the majority of the injected aqueous flow, it is expected that they will be successfully stopped, forcing water floods into the less permeable regions [4] [14] [15]. The current study aimed at screening a number of 
bacterial isolates for their ability of biopolymer production and selecting the most efficient one in production to test the ability of the product to close the high permeability openings of the oil reservoir rocks.

\section{Material and methods}

\section{Screening of biopolymer production}

In this study, 21 diagnosed bacterial isolates were used [16] which were isolated from various oil sources. for screening of biopolymer production activity $2 \mathrm{ml}$ of overnight broth culture of each isolates were add to $250 \mathrm{ml}$ Erlenmeyer flask containing $100 \mathrm{ml}$ of sterilized biopolymer producing media modification of [17] including (per litter distilled water) $40 \mathrm{~g}$ sucrose as a carbon source, $0.5 \mathrm{~g} \mathrm{NaNO}_{3}, 1.0 \mathrm{~g}$ yeast extract, $0.5 \mathrm{~g} \mathrm{KH}_{2} \mathrm{PO}_{4}, 0.25 \mathrm{~g}$ $\mathrm{MgSO}_{4} \cdot 7 \mathrm{H}_{2} \mathrm{O}, \mathrm{pH} 7.0 .1 \mathrm{ml}$ stock solution was composed of $(\mathrm{g} / \mathrm{L}): \mathrm{FeCl}_{3} \cdot 6 \mathrm{H}_{2} \mathrm{O} 0.08, \mathrm{CuSO}_{4}$ $5 \mathrm{H}_{2} \mathrm{O} 0.075, \mathrm{H}_{3} \mathrm{BO}_{3} 0.15$ solid media were prepared by the addition of $15 \mathrm{~g} \cdot \mathrm{L}-1$ agar. Wet and viscous colonies were selected and identified as the bacteria that produce biopolymers.

The Erlenmeyer flask was infected with $2 \% 12$ hour old inoculum and incubated for 72 hours at $30^{\circ} \mathrm{C}$ on a shaker at $180 \mathrm{rpm}$. The culture was centrifuged for 30 minutes at 12,000 $\mathrm{rpm}$, and the exopolysaccharide-containing cell-free supernatant was used to assess viscosity.

\section{Viscosity measurement}

Biopolymers production was detected by measuring the viscosity of supernatant solution using a glass capillary viscometer at $25^{\circ} \mathrm{C}$ in a refrigerated bath and circulator. The sample broth was first cooled in a refrigerated bath for 2 minutes before viscosity was measured [18].

\section{Sudan black stain}

The biopolymer production by the microbes can be confirmed by staining with Sudan black stain in two methods:-

\section{- Slide Method}

After heat fixing the smear, the slide was submerged in 5 percent Sudan Black (w/v in $70 \%$ ethanol) staining for 5 minutes and allowed to dry in air, the excess stain was de-stained using xylene several times and blot dried with absorbent paper, safranin was added for 30 seconds and washed with tap water and dried. Under an oil immersion microscope, the stained cells were examined. The biopolymer granules appeared as blue black droplets and cytoplasm part of microorganisms appeared as pink color [19].

\section{- $\quad$ Plate Method}

In this method grown colonies on agar plates were flooded with 3\% of Sudan Black (w/v in 70\% ethanol) solution for 20 min. Later, the ethanol solution was added as a dye remover solution of Sudan black stain .Finally the solution was drained off and observed for screening of biopolymer producers as black mucous colonies [20].

\section{Extraction of Crude biopolymer:}

Centrifugation of broth culture yielded cell-free supernatant, which was then treated with half volume of distilled water before being placed in a shaking incubator at $30 \mathrm{oC}$ for one hour. To precipitate the extracellular protein fractions, 7\% trichloroacetic acid (TCA) was added to the cell-free supernatant. The protein fractions were then collected by centrifugation at $9,000 \mathrm{rpm}$ for 30 minutes at $4^{\circ} \mathrm{C}$. To the clear supernatant, an equal volume of $100 \%$ 
ethanol was added. Precipitation was gathered around the glass rod. Four to five times the dissolving and precipitation process was repeated until uniform white precipitates were obtained. Vacuum desiccators were used to dry the sample. The crude biopolymer was dialyzed and lyophilized against distilled water [21].

\section{Characterization of polymer using Fourier Transform Infra-Red (FTIR)}

To determine the basic functional groups of the two partial purified polymer, Fourier Transform Infra-Red (FT-IR) spectroscopy analysis in the Chemistry department /College of Sciences/ University of Basra was used. $1 \mathrm{mg}$ of dried biopolymer was milled with $100 \mathrm{mg}$ of $\mathrm{KBr}$ to form a very fine powder to be analyzed by FT-IR spectra at the wavelength of 400 $4000 \mathrm{~cm}-1$ [22].

\section{Production of extracellular polymeric substance to seal fracture zones in tested cores} Three oily saturated cores having high permeability zone and deep cracks were selected in this experiment, the core plugs were dried in a hot air oven at $65^{\circ} \mathrm{C}$ for $24 \mathrm{~h}$ and mass of each dray core was measured using a sensitive balance then saturated with crude oil using vacuum pump .each core was placed separately to $500 \mathrm{ml}$ Erlenmeyer flask contain 250 $\mathrm{mL}$ of sterile polymer production medium which mentioned previously. Each flask was inoculated with $2 \%$ of the bacterial suspension of broth culture of Bacillus licheniformis strain CC91 and incubated at $30^{\circ} \mathrm{C}$ for 7 days. One of cores treated as control without bacteria.

\section{Results and discussion}

\section{Screening of biopolymer producing bacteria}

Twenty-one of bacterial isolates were tested for the biopolymer production. Ten isolates were observed in sucrose containing media. Many researchers showed using sucrose as carbon source in biopolymer production media [23] [24] [25].Each colony was grown clearly on the nutrient and give appositive result in screening test the best result showed with two gram positive strains Bacillus licheniformis strain CC91 and Bacillus thuringiensis strain LU3. Biopolymer was reported to be created by a huge number of gramme positive bacteria in prior studies. [26],[27],[28].

\subsubsection{Viscosity measurement}

After an incubation period of 3-5 days, a viscosity was observed in the medium containing the polymer-forming bacteria that could be distinguished during shaking of the bottle, as well as the presence in Figure 1. Supernatant viscosity test for all isolates indicated that there are 6 isolates with the highest values ranged between (3.7643-2.4543 c.st) Table 1 .The two highest values recorded (3.7643 c.st) and (3.6942 c.st) for Bacillus licheniformis strain CC91, Bacillus thuringiensis strain LU3 respectively, as shown in Figure 2. The results of the viscosity measurement in our study were identical to the results reported by Illias et al. [29] in the viscosity measurements of several biopolymers production strains of the genus Bacillus spp. used in their study. According to Lee \& Tripathi, (2005) [30], the viscosity measuring approach is very relevant in many chemical, biological, and medicinal applications where sample numbers are limited. 


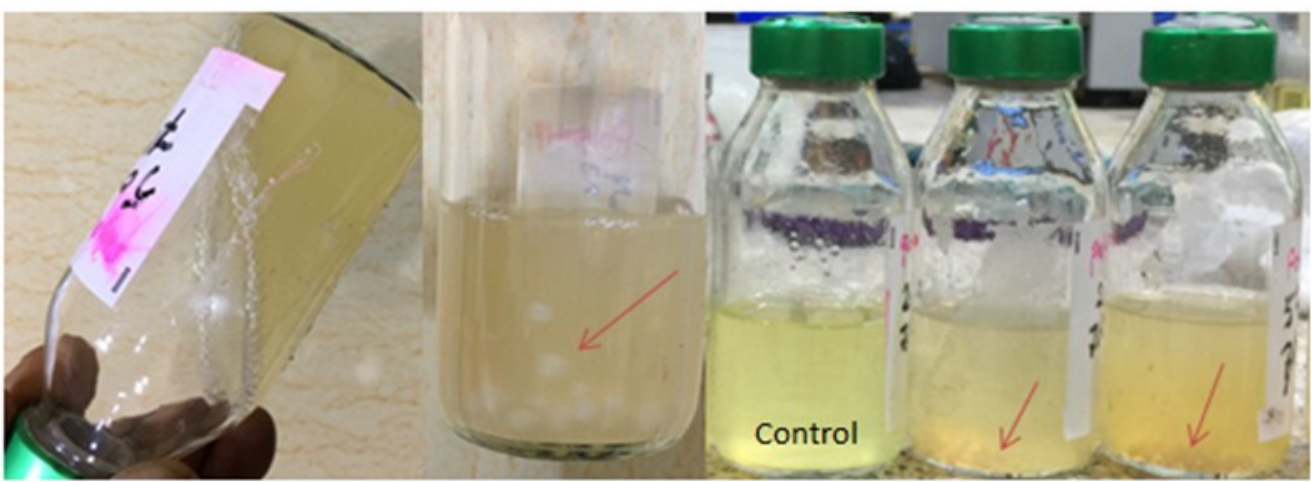

Fig. 1. Viscosity of biopolymer producing

\section{Table 1: Viscosity measurements of isolates}

\begin{tabular}{|l|l|l|l|}
\hline \multicolumn{2}{|l|}{ Strain } & $\begin{array}{l}\text { Viscosity } \\
\text { centistokes (c.st) }\end{array}$ & Sudan black stain \\
\hline 1 & Control & 0.8334 & - \\
\hline 2 & Bacillus cereus strain ASWISA1 & 1.5432 & - \\
\hline 3 & Lysinibacillus boronitolerans strain SWTPB36 & 0.9987 & - \\
\hline 4 & Bacillus subtilis strain HDZK-BYSB7 & 1.0876 & - \\
\hline 5 & Bacillus thuringiensis strain ASWISA2 & 2.2655 & + \\
\hline 6 & Enterobacter aerogenes strain B19 & 1.6543 & - \\
\hline 7 & Bacillus sonorensis strain ASWISA3 & 1.8766 & - \\
\hline 8 & Bacillus licheniformis strain CC91 & 3.7643 & - \\
\hline 9 & Bacillus cereus strain ASWISA4 & 1.2333 & - \\
\hline 1 & Bacillus subtilis ASWISA5 & 1.4432 & - \\
0 & & & - \\
\hline 1 & Bacillus subtilis ASWISA7 & 1.4236 & \\
\hline 1 & & & - \\
\hline 1 & Pseudomonas stutzeri strain ASWISA6 & 1.6675 & \\
\hline 2 & & & - \\
\hline 1 & Bacillus cereus strain A & 1.8776 & \\
\hline 3 & & 0.9877 & \\
\hline 1 & Bacillus cereus ASWISA8 & 3.6942 & \\
\hline 4 & & & - \\
\hline 1 & Bacillus cereus Strain US04 & & \\
\hline 5 & & Bacillus thuringiensis strain LU3 & \\
\hline 6 & & & - \\
\hline 1 & & \\
\hline
\end{tabular}




\begin{tabular}{|l|l|l|l|}
\hline 1 & Bacillus paramycoides strain ASWISA9 & 2.4543 & + \\
7 & & 2.5655 & + \\
\hline 1 & Bacillus paramycoides strain ASWISA10 & & \\
\hline 1 & Brevibacillus brevis strain ASWISA11 & 1.0987 & + \\
9 & & 0.8766 & - \\
\hline 2 & Enterobacter cloacae strain ASWISA12 & & - \\
\hline 0 & & 1.0432 & - \\
\hline 2 & Enterobacter cloacae strain FC1375 & 0.9232 & \\
\hline 2 & Bacillus cereus strain LDPE1 & & \\
\hline
\end{tabular}

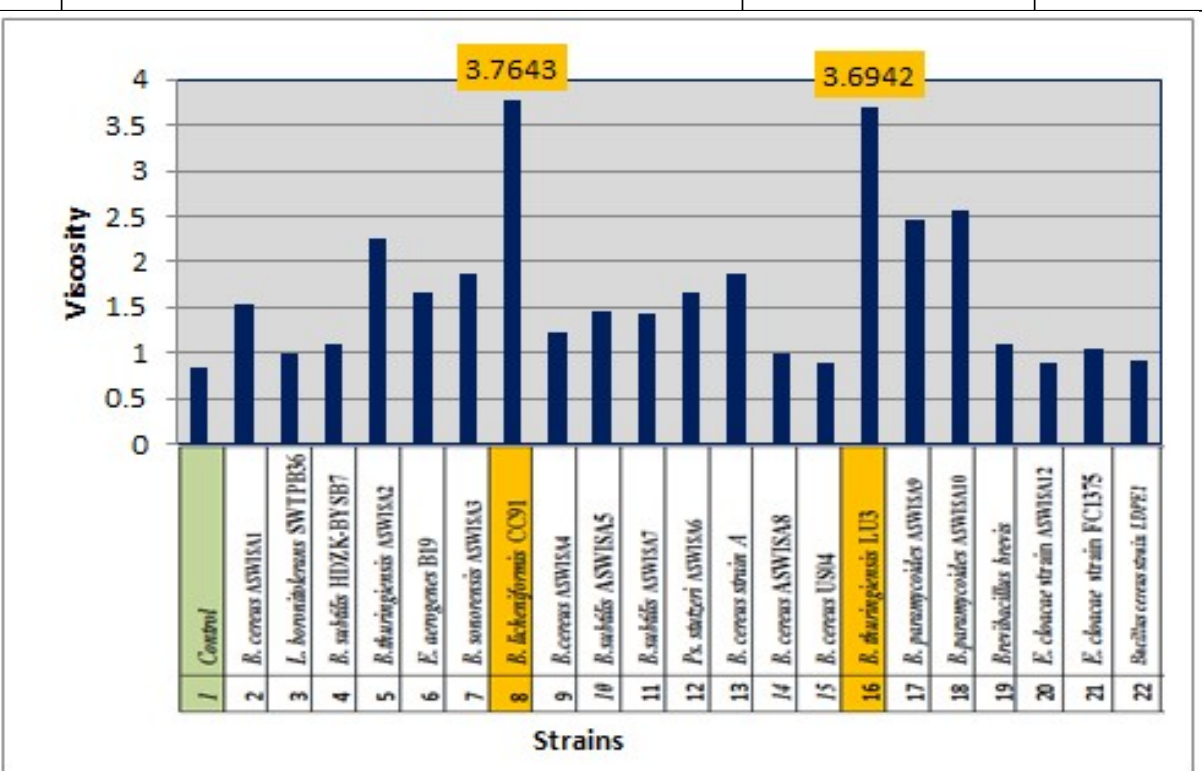

Fig. 2. Viscosity values for supernatant of isolates

\section{Sudan black stain}

Use of Sudan black stain in slides and plate method gave positive results similar to all isolates that gave positive results of viscosity measurements testing. Figure 3 shows the black color of sticky colonies growing on the plates for both isolates for Bacillus licheniformis strain CC91, Bacillus thuringiensis strain LU3. As well as spores stained in black color while the cells stained in red color in slide stain method Figure 4. Yasin \& Al-Mayaly,2020 [31] had the same finding, showing granules loaded with black staining, as biopolymer granules can be seen as dark spots under the light microscope. 

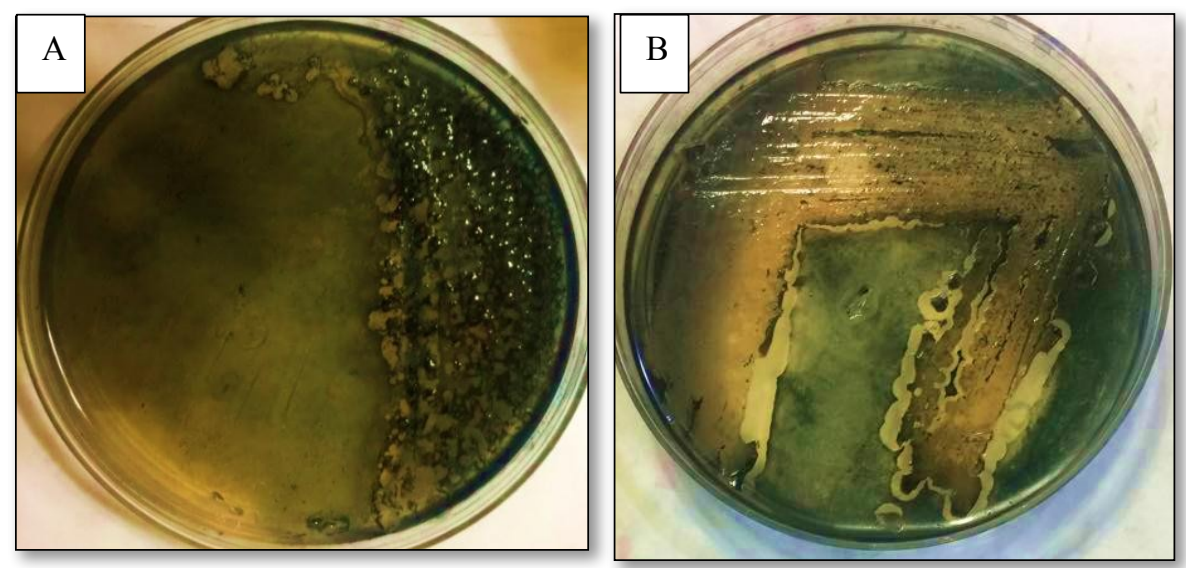

Fig. 3. Sudan black stain plate methods (A)

Bacillus licheniformis strain CC91(B) of Bacillus thuringiensis strain LU3
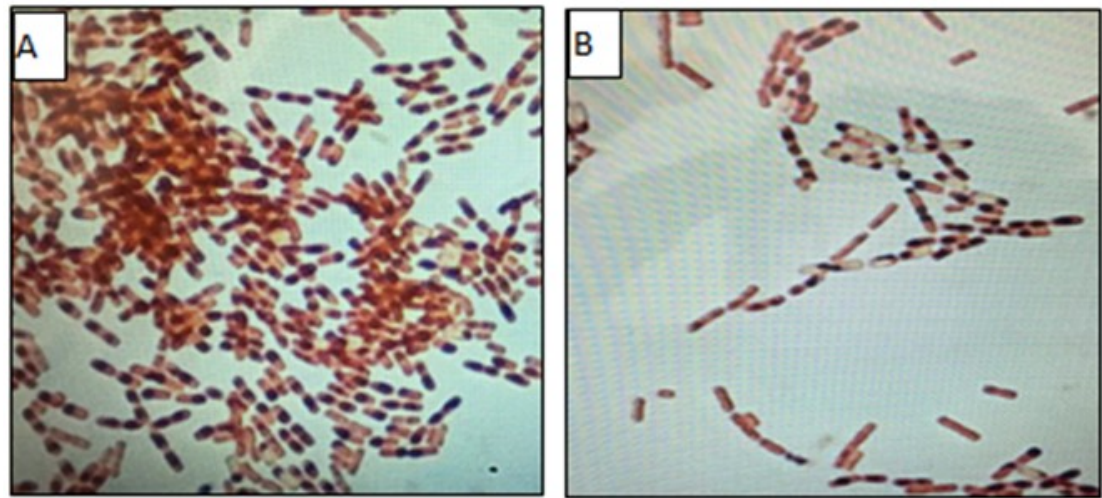

Fig. 4. Sudan black stain slide methods (A) Bacillus licheniformis strain CC91(B) Bacillus thuringiensis strain LU3

\section{Extraction of Crude biopolymer}

The results of the extraction of biopolymer using solvents are shown to separate the top layer containing the polymer for each of the three isolates: Bacillus licheniformis strain CC91(8), Bacillus thuringiensis strain LU3as shown in the Figure 5. 


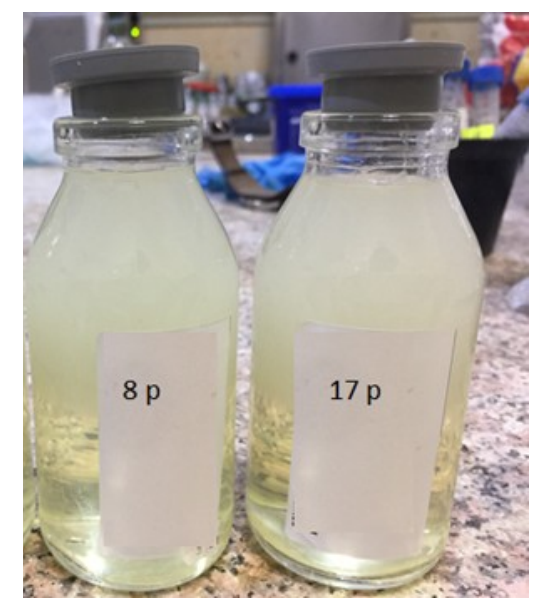

Fig.5. - Extracted of biopolymer with solvents

\section{Characterization of polymer using Fourier Transform Infra-Red (FTIR)}

Figure 6 illustrates FTIR studies of extracted biopolymer produce by Bacillus licheniformis strain CC91 Which was chosen as the best isolate for the production of biopolymers. The $\mathrm{OH}$ (Hydroxyl) group is represented by band 3471, while the $\mathrm{C}=\mathrm{O}$ (Carbonyl) and $\mathrm{COO}$ (ester) groups are represented by band 1743 . The band at 1458 represents $\mathrm{CH}$, which has asymmetrical stretching and bending vibrations in the $\mathrm{CH} 3$ group, while the band at 1377 represents the $\mathrm{COH}$ bond. $\mathrm{C}-\mathrm{O}$ bonding was seen in bands stretching from 1095 to 1283 . The investigated results confirmed that the recovered biopolymer component was Polyhydroxybutyrates, as reported by Arun et al. (2009) [32]. (PHB). Alarfaj et al. (2015) [28] also came to the same conclusion.

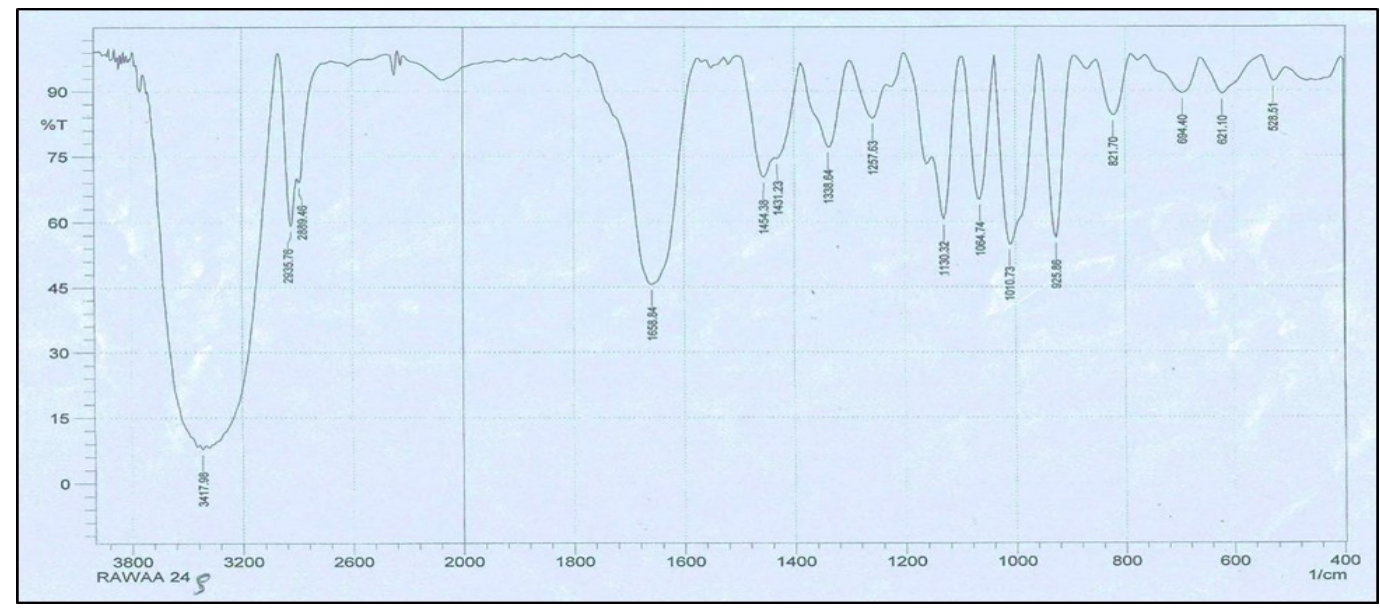

Fig.6. FTIR of extracted biopolymer produce by Bacillus licheniformis strain CC91

\section{Production of extracellular polymeric substance to seal fracture zones in tested cores}


The results of the inoculated of Bacillus licheniformis strain CC91 bacteria in biopolymer production culture medium with the presence of the cores selected from the oil fields that contain cracks and fractures showed a sticky layer of extracellular polymer and the biomass of bacteria growing in all the cracks and fractures to form a sticky layer to close these openings as in the Figure 7 that shows the nature of the cores before (A) and after culturing (C) comparing with the core treated without bacteria (B). Several studies have indicated the use of various bacterial strains in the process of reducing high permeability areas of oil reservoir that follow the mechanism of water injection in oil recovery processes to increase oil recovery. Bacillus licheniformis strain BNP29 was able to produce considerable volumes of biomass, polymer with selective plugging, and boosted oil recovery from 9.3 to 22.1 percent, according to Yakimov et al. (1997)[33]. Suthar et al. (2009) [34] utilised Bacillus licheniformis TT33 in the sand pack to exhibit bacterial growth and biofilm formation, resulting in a $27.7 \pm 3.5$ oil recovery.

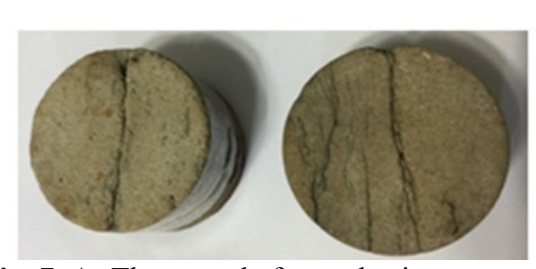

Fig. 7. A- The cores before culturing

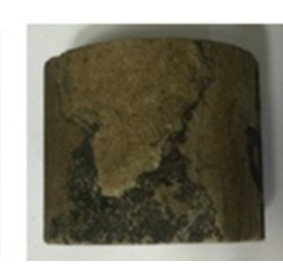

B- without bacteria

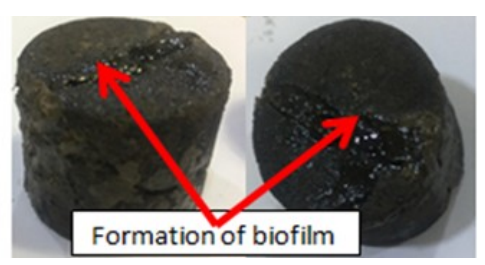

C- The cores after culturing

\section{Conclusion}

In the current study, biopolymer production was investigated for 22 environmental bacterial isolates, six of which showed the possibility of biopolymer production related to the viscosity measurement of the medium, as well as the use of Sudan black stain for the growth bacterial colonies or fixed cells. The isolate Bacillus licheniformis strain CC91 was chosen from one of twenty environmental isolates genetically diagnosed as the best isolates that have the ability to produce biopolymers.

FTIR studies of extracted biopolymer produce by Bacillus licheniformis strain CC91 confirming that the extracted biopolymer compound was Polyhydroxybutyrate (PHB).

The isolate Bacillus licheniformis strain CC91 showed ability to produced extracellular polymeric substance to seal fracture zones in tested core samples taken from an oil reservoir that may subsidize to the processes of microbial oil recovery (MEOR).

\section{References}

[1] Smith, A. M., Moxon, S., \& Morris, G. A. Biopolymers as wound healing materials. In Wound healing biomaterials (pp. 261-287). Woodhead Publishing.

[2] Xia, S., Zhang, L., Davletshin, A., Li, Z., You, J., \& Tan, S. Application of Polysaccharide Biopolymer in Petroleum Recovery. (2020). Polymers, 12(9), 1860.

[3] Hovland, B. (2015). Assessment of the biodegradability of xanthan in offshore injection water (Master's thesis, The University of Bergen).

[4] Sen, R. Biotechnology in petroleum recovery: the microbial EOR. (2008). Progress in energy and combustion Science, 34(6), 714-724. 
[5] Costa, O. Y., Raaijmakers, J. M., \& Kuramae, E. E. Microbial extracellular polymeric substances: ecological function and impact on soil aggregation. (2018). Frontiers in microbiology, 9, 1636.

[6] Ates, O.. Systems biology of microbial exopolysaccharides production. (2015). Frontiers in bioengineering and biotechnology, 3, 200.

[7] De Vuyst, L., De Vin, F., Vaningelgem, F., \& Degeest, B. Recent developments in the biosynthesis and applications of heteropolysaccharides from lactic acid bacteria. (2001). International Dairy Journal, 11(9), 687-707.

[8] Shaaban, M. T., \& Mowafy, E. I. (2012). Studies on incubation periods, scale up and biodisintegration of poly- $\beta$-hydroxybutyrate (PHB) synthesis by Stenotrophomonas (pseudomonas) maltophilia and Pseudomonas putida. Egypt. J. Exp. Biol.(Bot.), 8, 133-140.

[9] Goodman, S. H. Investigation into the Potential Application of Microbial Enhanced Oil Recovery on Unconventional Oil: (2018). A Field Specific Approach (Doctoral dissertation, University of Liverpool).

[10] De Vuyst, L., \& Vermeire, A. Use of industrial medium components for xanthan production by Xanthomonas campestris NRRL-B-1459. (1994). Applied microbiology and biotechnology, 42(2), 187-191.

[11] Sandford, P. A. Exocellular, microbial polysaccharides. (1979). Advances in carbohydrate chemistry and biochemistry, 36, 265-313.

[12] Nwidee, L. N., Theophilus, S., Barifcani, A., Sarmadivaleh, M., \& Iglauer, S. EOR processes, opportunities and technological advancements. (2016). Chemical Enhanced Oil Recovery (cEOR)-a Practical Overview, 2-52.

[13] Song, C., Chen, Y., \& Wang, J. Plugging high-permeability zones of oil reservoirs by microbially mediated calcium carbonate Precipitation. (2020). ACS omega, 5(24), 1437614383

[14] Guo, S., Nighot, M., Al-Sadi, R., Alhmoud, T., Nighot, P., \& Ma, T. Y. Lipopolysaccharide regulation of intestinal tight junction permeability is mediated by TLR4 signal transduction pathway activation of FAK and MyD88. (2015). The Journal of Immunology, 195(10), 49995010 .

[15] Sabooniha, E., Rokhforouz, M. R., \& Ayatollahi, S. Pore-scale investigation of selective plugging mechanism in immiscible two-phase flow using phase-field method. (2019). Oil \& Gas Science and Technology-Revue d'IFP Energies nouvelles, 74, 78.

[16] Hamzah, A. F., Abd-Alsahib, W. H., \& Mahdi, S. S. Isolation and identification new bacterial strains isolated from different sources of Al-Rafidiyah oil field in Iraq. (2020). Catrina: The International Journal of Environmental Sciences, 21(1), 15-22.

[17] She, Y. H., Zhang, F., Xiang, T. S., Liu, B. B., Zhao, L. P., Zhou, L. G., \& Shu, F. C. Microbial diversity in petroleum reservoirs analyzed by PCR-DGGE. (2005). Acta Ecologica Sinica, 25(2), 237-242.

[18] Illias, R. M., Ooi, S. W., Idris, A. K., \& Rahman, W. A. W. A.. Isolation and characterization of halotolerant aerobic bacteria from oil reservoir. (2001). Jurnal Teknologi, 1â-10.

[19] Wei, Y. H., Chen, W. C., Huang, C. K., Wu, H. S., Sun, Y. M., Lo, C. W., \& Janarthanan, O. M. (2011). Screening and evaluation of polyhydroxybutyrate-producing strains from indigenous isolate Cupriavidus taiwanensis strains. International journal of molecular sciences, 12(1), 252-265..

[20] Mehta, V., Patel, E., Vaghela, K., Marjadi, D., \& Dharaiya, N. Production of biopolymer from dairy waste: an approach to alternate synthetic plastic. (2017). Int. J. Res. Biosci., 6(4), 1-8.

[21] Jamil, N., \& Ahmed, N. Production of biopolymers by Pseudomonas aeruginosa isolated from marine source. (2008). Brazilian archives of Biology and Technology, 51(3), 457-464.

[22] Aparna, A., Srinikethan, G., \& Smitha, H. Production and characterization of biosurfactant produced by a novel Pseudomonas sp. 2B. (2012) . Colloids and Surfaces B: Biointerfaces, 95, 23-29. 
[23] Jiang, G., Hill, D. J., Kowalczuk, M., Johnston, B., Adamus, G., Irorere, V., \& Radecka, I. Carbon sources for polyhydroxyalkanoates and an integrated biorefinery. (2016). International journal of molecular sciences, 17(7), 1157.

[24] Ahmad, S., Amir, A., Zafaryab, M., Osama, K., Faridi, S. A., Siddiqui, M. H., ... \& Khan, M. A.. Production and characterization of polyhydroxybutryrate biopolymer from Azohydromonas australica using sucrose as a sole carbon source.(2017). J. Microb. Biochem. Technol., 9, 8286.

[25] Jeong, M. S., Noh, D. H., Hong, E., Lee, K. S., \& Kwon, T. H. Systematic modeling approach to selective plugging using in situ bacterial biopolymer production and its potential for microbial-enhanced oil recovery. (2019). Geomicrobiology Journal, 36(5), 468-481.

[26] Mergaert, J., \& Swings, J. Biodiversity of microorganisms that degrade bacterial and synthetic polyesters.(1996). Journal of industrial microbiology, 17(5), 463-469.

[27] Verlinden, R. A., Hill, D. J., Kenward, M. A., Williams, C. D., \& Radecka, I. Bacterial synthesis of biodegradable polyhydroxyalkanoates. (2007). Journal of applied microbiology, 102(6), 1437-1449.

[28] Alarfaj, A. A., Arshad, M., Sholkamy, E. N., \& Munusamy, M. A.. Extraction and Characterization of Polyhydroxybutyrates (PHB) from Bacillus thuringiensisKSADL127 Isolated from Mangrove Environments of Saudi Arabia.(2015). Brazilian Archives of Biology and Technology, 58(5), 781-788.

[29] Illias, R. M., Ooi, S. W., Idris, A. K., \& Rahman, W. A. W. A. Isolation and characterization of halotolerant aerobic bacteria from oil reservoir.(2001). Jurnal Teknologi, 1â-10.

[30] Lee, J., \& Tripathi, A. Intrinsic viscosity of polymers and biopolymers measured by microchip. (2005). Analytical chemistry, 77(22), 7137-7147.

[31] Yasin, A. R., \& Al-Mayaly, I. K. Isolation and identification of polyhydroxyalkanoates producing bacteria from biopolymers waste in soil. (2020). In IOP Conference Series: Materials Science and Engineering (Vol. 928, No. 6, p. 062014). IOP Publishing.

[32] Arun, A., Arthi, R., Shanmugabalaji, V., \& Eyini, M.. Microbial production of poly- $\beta$ hydroxybutyrate by marine microbes isolated from various marine environments. (2009). Bioresource technology, 100(7), 2320-2323.

[33] Yakimov, M. M., Amro, M. M., Bock, M., Boseker, K., Fredrickson, H. L., Kessel, D. G., \& Timmis, K. N. The potential of Bacillus licheniformis strains for in situ enhanced oil recovery. (1997). Journal of Petroleum Science and Engineering, 18(1-2), 147-160.

[34] Suthar, H., Hingurao, K., Desai, A., \& Nerurkar, A. Selective plugging strategy based microbial enhanced oil recovery using Bacillus licheniformis TT33. (2009). Journal of microbiology and biotechnology, 19(10), 1230-1237. 